\title{
Gojeg Lesung: Pengembangan Seni Gejog Lesung Hasil Penyuluhan Seni Teater di Desa Sabdodadi, Bantul, Yogyakarta
}

\author{
Rano Sumarno \\ Jurusan Teater, Fakultas Seni Pertunjukan \\ Institut Seni Indonesia Yogyakarta \\ Jalan Parangtritis Km 6,5 Sewon, Bantul, Daerah Istimewa Yogyakarta 55188 \\ No. Tlp.: +6281910064398, E-mail: ranosumarno990@gmail.com
}




\title{
Gojeg Lesung: Pengembangan Seni Gejog Lesung Hasil Penyuluhan Seni Teater di Desa Sabdodadi, Bantul, Yogyakarta
}

\author{
Rano Sumarno \\ Jurusan Teater, Fakultas Seni Pertunjukan \\ Institut Seni Indonesia Yogyakarta \\ Jalan Parangtritis Km 6,5 Sewon, Bantul, Daerah Istimewa Yogyakarta 55188 \\ No. Tlp.: +6281910064398, E-mail: ranosumarno990@gmail.com
}

\begin{abstract}
Abstrak
Gojeg Lesung pengembangan dari seni Gejog Lesung merupakan strategi mempromosikan Desa Sabdodadi dalam aktivitasnya di bidang seni budaya. Penyuluhan seni ini bertujuan untuk: (1) meningkatkan kualitas kelompok teater Sanggar Kolingin menjadi kelompok kesenian yang mandiri dan lebih diterima di tengah masyarakat; (2) memberikan pemahaman yang tepat bagi masyarakat tentang arti pentingnya seni-budaya lokal sebagai penyeimbang masuknya budaya asing; (3) melestarikan dan menumbuhkan minat terhadap seni dan budaya lokal; dan (4) membangun kebersamaan dan menciptakan kreativitas masyarakat setempat. Metode yang digunakan dalam penyuluhan seni ini melalui tiga tahapan, yakni penanaman konsep, penanaman minat, dan penanaman bakat. Hasil yang dicapai dari penyuluhan seni ini telah melahirkan kreasi baru seni pertunjukan bernama Gojeg Lesung dalam genre teater rakyat yang memiliki struktur pertunjukan: tetalu, bubuka, tarian komedi, lakon, dan penutup. Peran serta pemerintah dan institusi seni diperlukan dalam kelanjutan penyuluhan seni ini karena masyarakat setempat membutuhkan ruang pentas untuk melanjutkan eksistensinya memasyarakatkan seni Gojeg Lesung.
\end{abstract}

Kata kunci: penyuluhan, Gejog Lesung, Gojeg Lesung

Gojeg Lesung: The Development of Gejog Lesung Art

Results of Theater Arts Training in Sabdodadi Village, Bantul, Yogyakarta

\begin{abstract}
Gojeg Lesung, developed from Gejog Lesung art is a strategy to promote Sabdodadi village in its arts and culture activity. The counseling aims to: (1) improve the quality of Sanggar Kolingin theater group to be independent and well-received in society; (2) give correct understanding to society the importance of local arts and culture as the balancing factor from foreign culture; (3) conserve and grow the interest in local arts and culture; and (4) build togetherness and creating creativity in locals. The method used in the art training is done through three steps, which are the concept building, interest building, and talent building. Results gained from the art counseling creates a new performance art titled Gojeg Lesung in folk theater genre with structure: tetalu (7 instruments opening), bubuka (prayers / calls to ancient spirit opening), comedy dance, lakon (role-play), and closing. Government and arts institution support are highly in need for the continuity of this art training as the locals need stage area to continue their existence in promoting and spreading Gojeg Lesung art.
\end{abstract}

Keywords: counseling, Gejog Lesung, Gojeg Lesung 


\section{PENDAHULUAN}

Sanggar Komunitas Kali Winongo Indah (Kolingin) terletak di wilayah Sabdodadi RT 02, Manding Serut, Bantul, Daerah Istimewa Yogyakarta. Desa yang terletak di bantaran kali sepanjang $17 \mathrm{~km}$ tersebut statusnya kini telah tercatat sebagai salah satu desa budaya di Yogyakarta (Wicaksono, 2020). Sanggar Kolingin merupakan potensi andalan Sabdodadi dengan beragam seni pertunjukan yang tumbuh menggeliat di dalamnya, di antaranya Kesenian Jatilan Turonggo Seto (Manding Gading), Kesenian Bergodo Songgo Rumekso (Manding Gading), Kesenian Reog Manggoloyudo, Hasto Krido Budoyo (Manding), Paduan Suara Srikandi (Kadibeso), dan Karawitan Redisono (Keyongan Kidul).

Sebagian dari kelompok kesenian di sanggar ini terbilang telah mapan dan mandiri. Hal ini ditandai dengan jam terbang pementasan yang padat. Kesenian jatilan misalnya, kelompok ini bahkan sering diundang untuk pentas hingga keluar Yogyakarta. Kelompok lainnya ada kesenian bergodo yang selalu langganan tampil di acara festival baik tingkat desa, kabupaten, maupun provinsi. Namun, beberapa kesenian lainnya masih relatif sepi dan jarang manggung. Salah satunya adalah kelompok kesenian teater sehingga butuh upaya pembinaan agar mampu meningkatkan kualitas pertunjukannya.

Di sisi lain masyarakat setempat bersama para petinggi desa kini tengah berupaya menghidupkan kelompok kesenian kesenian tari dan teater. Pengembangan kelompok teater ini dimaksudkan untuk mewadahi komponen masyarakat yang memiliki ketertarikan di bidang tersebut. Remaja milenial menjadi target utama dalam penjaringan bakat tari dan teater dikarenakan minimnya ketertarikan mereka pada kesenian yang telah terbentuk sebelumnya.
Gempuran budaya global yang menggerus keberadaan budaya lokal sangat terasa dampaknya pada kelompok-kelompok kesenian di daerah. Pergeseran adat dan budaya tampaknya telah mengubah wajah-wajah anak negeri yang lebih memilih budaya asing untuk mereka banggakan. Invasi budaya impor yang mendapat respons positif masyarakat tanpa adanya filter dan penyeimbang dari budaya lokal telah mengakibatkan sebagaian besar masyarakat mengalami kerancuan dalam memahami nilai antara budaya asli milik Indonesia dan budaya asing.

Desa Sabdodadi adalah salah satu wilayah yang mulai merasakan dampak tersebut. Kekhawatiran masyarakat akan terputusnya kaderisasi dalam setiap kelompok kesenian semakin tinggi ketika kaum remaja sedikit demi sedikit semakin menjauh dari kesenian yang dimilikinya. Melihat kondisi tersebut, butuh suatu upaya serius dalam penanaman minat seni lokal pada generasi muda.

Seni teater dipandang kegiatan yang paling tepat dalam menjaring generasi muda untuk mengonservasi kearifan lokal setempat. Melalui seni teater nilai-nilai lokal akan tertanamkan karena lebih memungkinkan terjadinya akulturasi budaya. Kesenian lokal tetap dapat tumbuh meski cara pandangnya sesuai dengan selera anak muda saat ini. Maka, penyuluhan seni pertunjukan teater adalah upaya dalam menjawab permasalahan tersebut.

Pelatihan teater yang berbasis pada tradisi adalah solusi yang dicoba untuk ditawarkan dalam pemecahan permasalahan di Sanggar Kolingin. Artinya segala elemen dalam pertunjukan teater akan berbasis pada identitas lokal setempat. Elemen yang dimaksudkan adalah bentuk pertunjukan, lakon atau cerita, gaya akting, artistik, kostum, dll. Dengan solusi ini diharapkan kesenian teater akan 
tumbuh menjadi kelompok yang mandiri dan mampu menghidupi para pelakunya menjadi sejahtera.

\section{METODE PENGABDIAN}

Metode yang digunakan dalam penyuluhan seni ini adalah metode planting, yakni sebuah tahapan penyutradaraan bagi seorang sutradara. Seperti halnya bercocok tanam, menggarap pertunjukan teater juga memerlukan langkah-langkah cerdas agar pada akhirnya nanti bisa memanen hasil sesuai dengan harapan (Rano, 2017). Metode planting memiliki enam tahapan, namun dalam program penyuluhan seni ini hanya menggunakan tiga tahapan, yakni penanaman konsep, penanaman minat, dan penanaman bakat.

\section{a. Penanaman Konsep}

Penanaman konsep merupakan tahapan penyuluh memberikan pemahaman mengenai bentuk kesenian yang akan digarap. Langkah ini bertujuan agar seluruh peserta bisa memahami langkah apa saja yang harus dilalui untuk mewujudkan kesenian yang akan digarap. Materi yang diberikan kepada peserta penyuluhan adalah dengan menjelaskan prinsip-prinsip dari pertunjukan teater rakyat. Seni ketoprak, longser, lenong, ludruk, dll. dijelaskan secara detail dan diberikan pemahaman mengenai struktur pertunjukan, gaya permainan, hingga teknik permainan komedi dalam konsep teater rakyat. Selanjutnya seni Gejok Lesung yang telah dimiliki dan biasa dimainkan oleh masyarakat setempat dikupas adegan per adegan untuk mencari celah dalam pengembangan pertunjukan dan memasukkan unsur lakon ke dalamnya.

Setelah peserta penyuluhan memahami prinsip pertunjukan teater rakyat, selanjutnya penyuluh mulai menyosialisasikan rancangan konsep dari pertunjukan Gojeg Lesung dengan memberikan ilustrasi bentuk dari setiap adegan yang akan digarap. Sebagai catatan keberhasilan dari tahapan ini adalah ketika peserta penyuluhan yang merupakan seniman Gejok Lesung mampu bermigrasi spirit dari pertunjukan seni musik dan tari tradisi menjadi seni teater rakyat

\section{b. Penanaman Minat}

Penanaman minat merupakan upaya penyuluh dalam menyosialisasikan kesenian yang akan digarap agar memikat peserta penyuluhan. Keunggulan dan kelebihan seni Gojeg Lesung dijelaskan serta keseruan dan bahkan tantangan yang akan dihadapi pun dipaparkan secara gamblang.

Dalam tahapan ini penyuluh juga menjaring dan membagi peserta menjadi tiga kelompok (penabuh, penembang, penggojeg) sesuai dengan kemampuannya masing-masing. Kelompok penabuh dan penembang tidak mengalami perubahan yang signifikan, hanya saja suasana menabuh dan iringan tembang tidak lagi mengalir seperti pertunjukan Gejok Lesung karena dalam pertunjukan Gojeg Lesung musik dan tembang mengikuti alur dramatik dari lakon yang dimainkan, ditambah suasana komedi yang dibangun dari awal hingga akhir pertunjukan menjadi tantangan sendiri bagi kelompok ini.

Kelompok penggojeg adalah kelompok yang sebelumnya merupakan kelompok penari dalam pertunjukan Gejok Lesung, tentu saja kelompok ini menjadi tim yang mendapatkan tantangan paling serius karena dalam Gojeg Lesung tim ini tidak hanya menari, tetapi juga ditambah tugas membawakan cerita sekaligus dituntut harus lucu dan jenaka selama dalam pertunjukan.

\section{c. Penanaman Bakat}

Penanaman Bakat merupakan pelatihan skill dari masing-masing kelompok, tetapi berhubung penyuluh merupakan dosen teater, jadi program penyuluhan ini lebih pada 
menggarap kelompok gojegannya. Mengingat juga bahwa kelompok penabuh dan penembang memang sudah terbentuk sebelum penyuluh masuk ke sanggar ini. Tim penari ditanamkan bakat akting dari dasar hingga dilatih keberanian untuk menyampaikan humor yang lucu.

\section{HASIL DAN PEMBAHASAN}

Khalayak sasaran penyuluhan seni ini adalah ibu-ibu yang tergabung dalam kelompok seni Gejok Lesung di Sabdodadi. Mereka adalah para ibu rumah tangga yang berusia antara 35 tahun hingga 65 tahun. Kelompok ini berjumlah kurang lebih sebanyak 30 orang yang rutin latihan Gejok Lesung.

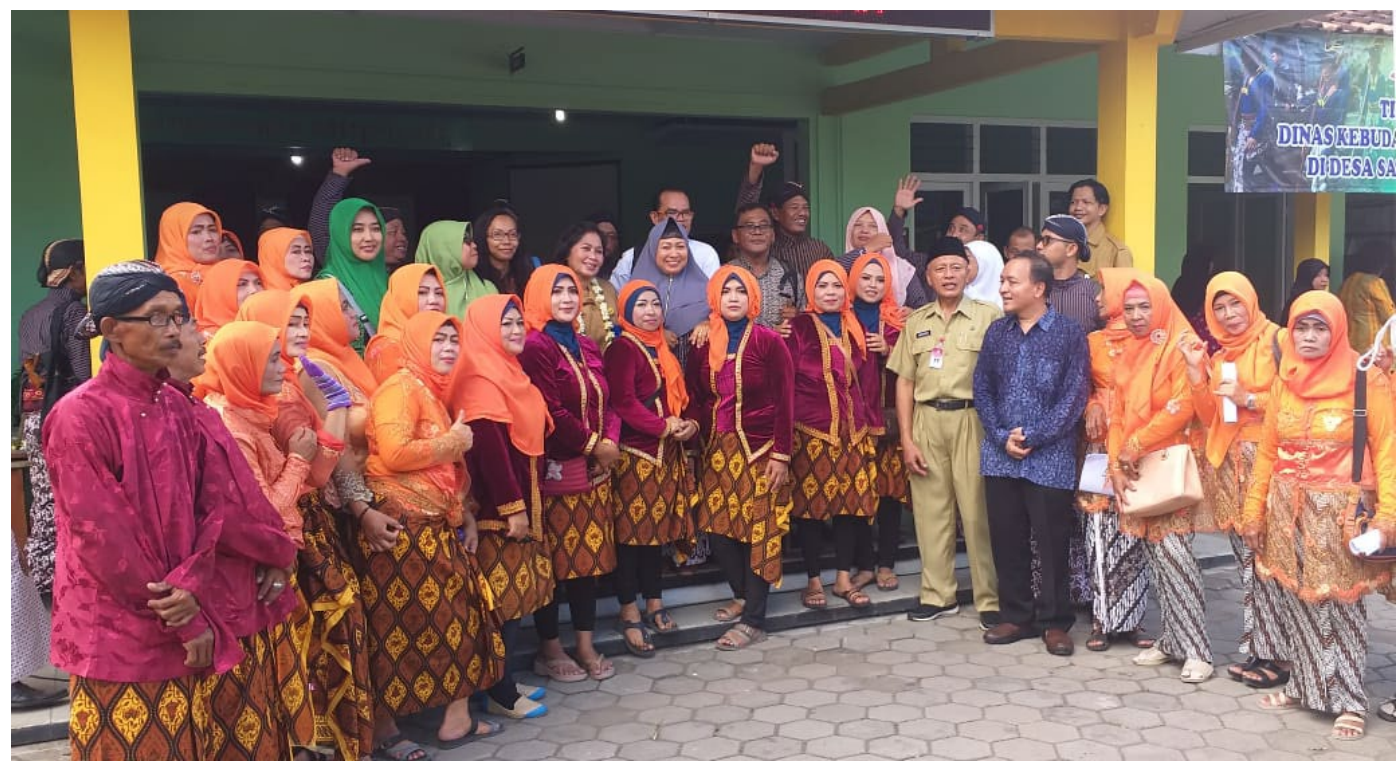

Gambar 1

Peserta penyuluhan seni bersama Lurah Sabdodadi

(Dokumentasi: Rano, 2019)

Tempat kegiatan penyuluhan dilaksanakan di Sanggar Kolingin. Tempat ini cukup representatif untuk melaksanakan pelatihan karena memiliki ruang yang cukup luas dengan area parkir yang strategis. Ke depan, lokasi ini akan menjadi objek wisata dengan pesona keindahan Kali Winongo sebagai andalan.
Kegiatan penyuluhan ini dilaksanakan dari Maret hingga Mei 2019 dengan mengambil waktu penyuluhan pada malam hari pukul 19.30 sampai dengan 22.30 WIB. Pemilihan waktu malam disepakati oleh seluruh peserta penyuluh mengingat anggota penyuluhan merupakan ibu-ibu pekerja, seperti pedagang, petani, dan karyawan. 


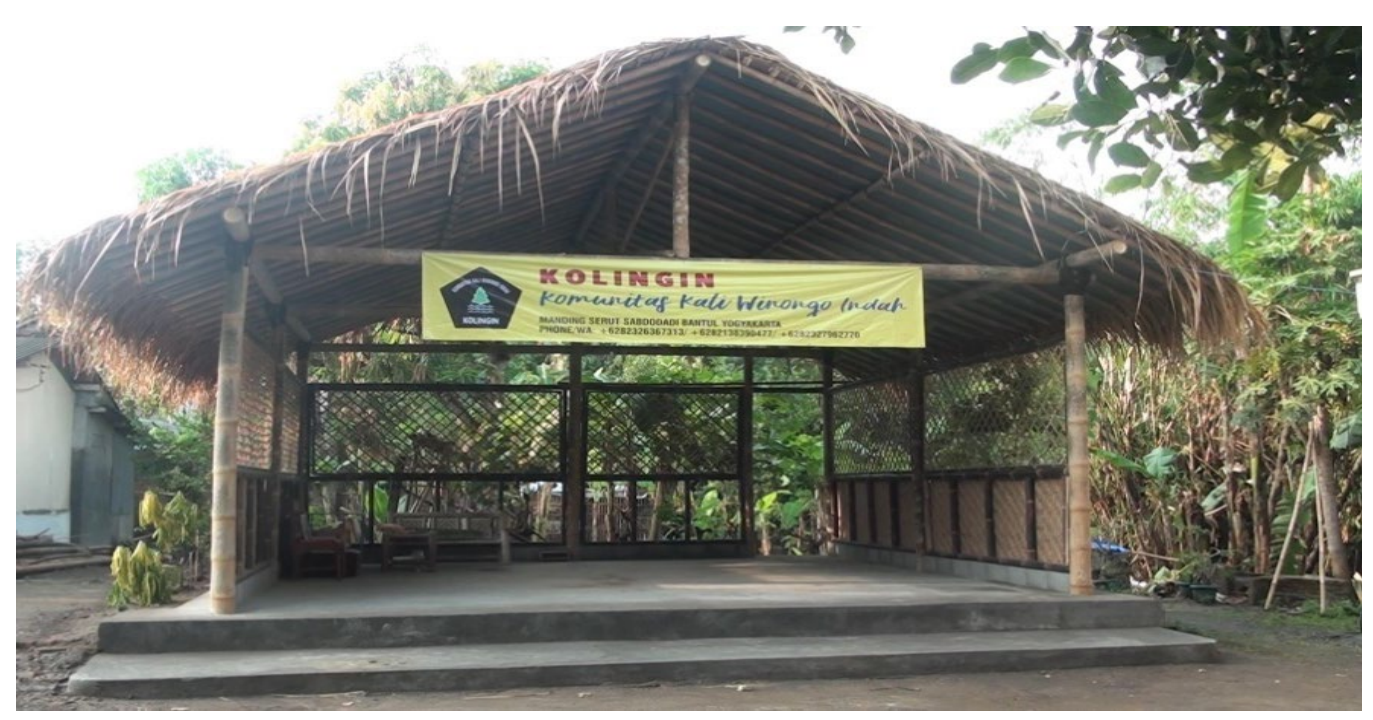

Gambar 2

Lokasi Sanggar Kolingin sebagai studio olah seni

(Dokumentasi: Rano, 2019)

Materi penyuluhan merupakan penciptaan kesenian baru bernama Gojeg Lesung. Kesenian ini merupakan pengembangan dari seni Gejog Lesung. Kata Gejog Lesung berasal dari kata gejog yang dalam bahasa Jawa memiliki arti tumbuk (ditutubahasa Jawa). Gejog tersebut dimaksudkan adanya proses menumbuk padi dengan memukulkan alu ke bagian badan Lesung (Suratmin, 1991). Lesung dan alu adalah alat 14 produksi padi tradisional, kemudian menurut perkembangannya lesung ini digunakan dalam musik atau kesenian tradisional, yaitu Gejog Lesung (Soedarsono, 1985).

Warga Desa Sabdodadi selama ini memiliki kegiatan kesenian Gejog Lesung yang sudah berjalan dan menjadi kegiatan rutin dari anggotanya. Gejog Lesung merupakan seni tradisi nyanyian tembang tradisi dengan iringan lesung. Pemain dibagi menjadi tiga kelompok, yakni kelompok penabuh yang bertugas mengiringi nyanyian menabuh alu dengan gejogan, kelompok kedua adalah penembang atau penyanyi yang membawakan lagu-lagu tradisioal Jawa, dan sebagai bentuk eksplorasi dari kesenian Gejok Lesung, penyuluh menciptakan pengembangan dengan menghadirkan satu kelompok baru yang bertugas membawakan cerita dengan semangat gojegan atau candaan. Penambahan kelompok ini untuk mengantisipasi kejenuhan dan memberikan kesegaran dalam seni Gejok. Kelompok Gojegan membawakan cerita yang berisi tentang kelucuan-kelucuan baik dari gerakan maupun isian cerita. 


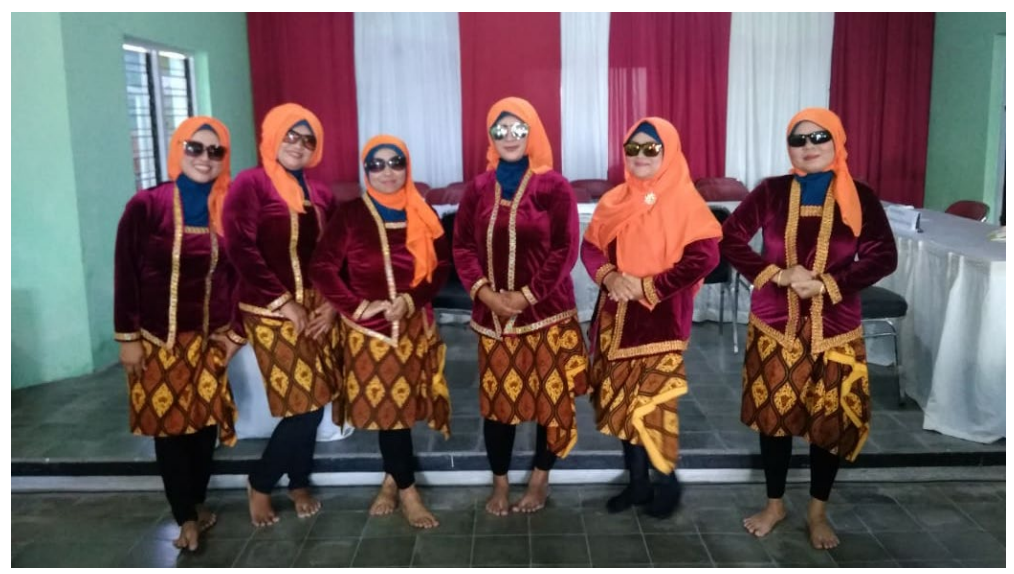

Gambar 3

Kelompok penari yang bertugas sebagai penggojeg

(Dokumentasi: Rano, 2019)

Seni Gojeg Lesung memiliki struktur pertunjukan: (1) tetalu, awalan dari pertunjukan ini dengan menabuh lesung membawakan lagu-lagu tradisi yang diiringi gejokan lesung; (2) bubuka, pembukaan yang disampaikan oleh pimpinan kelompok Gojeg Lesung dengan maksud dan ucapan sebagai pertanda pertunjukan akan segera dimulai; (3) tarian komedi, tarian yang dibawakan oleh kelompok gojegan dan diiringi oleh nyanyian. Gerakan tari ini dikoreo dengan gerakangerakan yang lucu dengan balutan kostum dan dandanan yang lucu pula; (4) lakon, rangkaian cerita singkat dengan guyonan-guyonan segar, biasanya disesuaikan dengan tema acara yang sedang berlangsung; dan (5) penutup, gabungan tarian, tembang, dan iringan secara bersamaan sebagai penutup dari pertunjukan ini.

Sampai saat ini pertunjukan Gojeg Lesung telah beberapa kali pentas baik sebagai undangan maupun dalam pementasan mandiri, di antaranya: (1) pementasan undangan oleh Lurah Sabdodadi dalam rangka penilaian potensi budaya oleh Dinas Kebudayaan Kabupaten Bantul, (2) pembukaan objek wisata Kali Winongo Bantul, (3) peringatan hari ulang tahun Wakil Bupati Bantul, (4) gelar hasil penyuluhan oleh LPPM ISI Yogyakarta dalam rangka Dies Natalis ISI Yogyakarta 2019, (5) pentas Agustusan Desa Manding Serut, Sabdodadi, dan (6) Parade Budaya Dinas Kesenian Kabupaten Bantul.

Setiap proses penciptaan seni pasti memiliki kendala atau masalah yang mungkin dapat menghambat atau memengaruhi hasil akhir dari kesenian tersebut, terlebih sebuah kegiatan penyuluhan yang notabene pesertanya bukan orang kesenian. Namun, kendala tersebut hendaklah menjadi pelajaran yang sangat penting dalam sebuah proses berkesenian.

Kendala yang dihadapi dalam penyuluhan di Sanggara Kolingin ini antara lain: (1) beragam profesi dari peserta penyuluhan mengakibatkan sering bergesernya jadwal latihan karena kerap disesuaikan dengan kesibukannya masing-masing; (2) peserta penyuluhan berasal dari beberapa RT yang tingkat persaingannya sangat tinggi. Hal ini sangat mengganggu karena rasa ego dari masing-masing RT tidak bisa terhindarkan. Sampai akhir dari penyuluhan ini beberapa peserta mundur karena gesekan ego tersebut; dan (3) fasilitas kostum dan make up menjadi tantangan tersendiri ketika seni Gojeg Lesung ini akan pentas karena sanggar ini tidak memiliki fasilitas tersebut sehingga peserta 
harus secara sukarela iuran sewa setiap kali akan pentas.

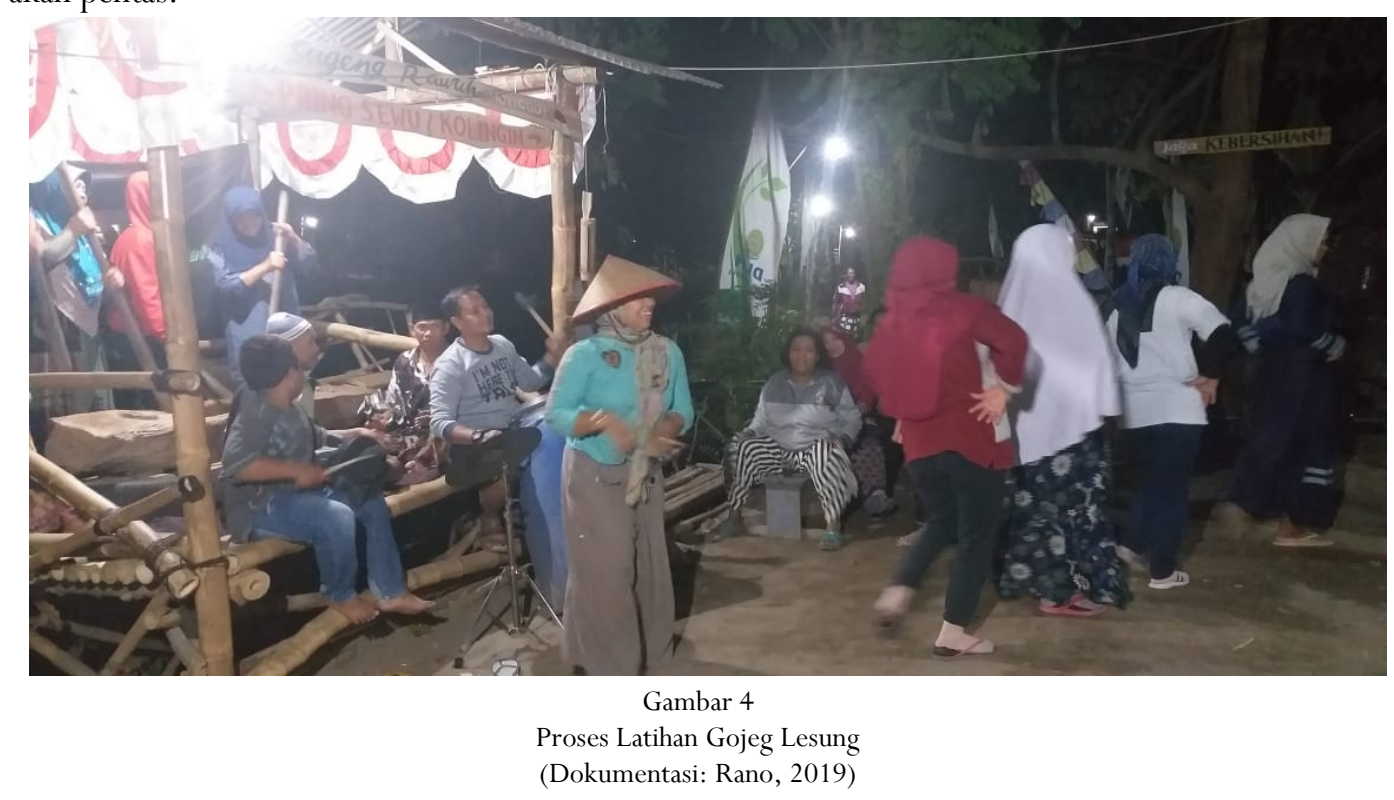

\section{SIMPULAN}

Puji serta syukur akhirnya penyuluhan seni ini dapat berjalan hingga menghasilkan pertunjukan seni baru yang bernama Gojeg Lesung. Kesenian ini merupakan hasil dari revitalisasi seni lesung dengan struktur pertunjukan tetalu, bubuka, tarian komedi, lakon, dan penutup. Selain indahnya irama musik dengan lirik-lirik lagu tradisi yang bersahaja, Gojeg Lesung juga menjanjikan sebuah tontonan yang akan mengundang gelak tawa bagi penikmatnya.

Partisipasi masyarakat di Desa Sabdodadi sangat mendukung kegiatan penyuluhan ini. Seluruh perangkat desa, dari Ketua RT, kepala dusun, hingga lurah setempat sangat mendukung dan mendorong hingga kegiatan penyuluhan ini berakhir. Keseriusan peserta dapat dilihat dari kehadiran setiap pelaksanaan penyuluhan ini berlangsung, setiap hari latihan selalu ramai dengan partisipasi yang maksimal.

\section{SARAN}

Sanggar Kolingin merupakan kegiatan masyarakat Dusun Manding Serut yang terletak di Desa Sabdodadi, Kecamatan Bantul. Sebagai sanggar yang kelak akan dijadikan andalan dalam pengembangan desa budaya dan masih membutuhkan banyak pelatihan dari berbagai unsur seni, masyarakatnya sangat terbuka dan menyambut hangat dalam menerima berbagai pelatihan. Untuk itu, LPPM ISI Yogyakarta bisa menjadikan mitra dalam kegiatan-kegiatan penyuluhan seni.

Tentu dalam pelaksanaan penyuluhan ini banyak pelajaran yang bisa diambil sebagai perjalanan penyuluh dalam menjalankan tugas. Semoga ke depan bisa mendapatkan kesempatan kembali dalam melaksanakan penyuluhan dengan materi yang berbeda. 


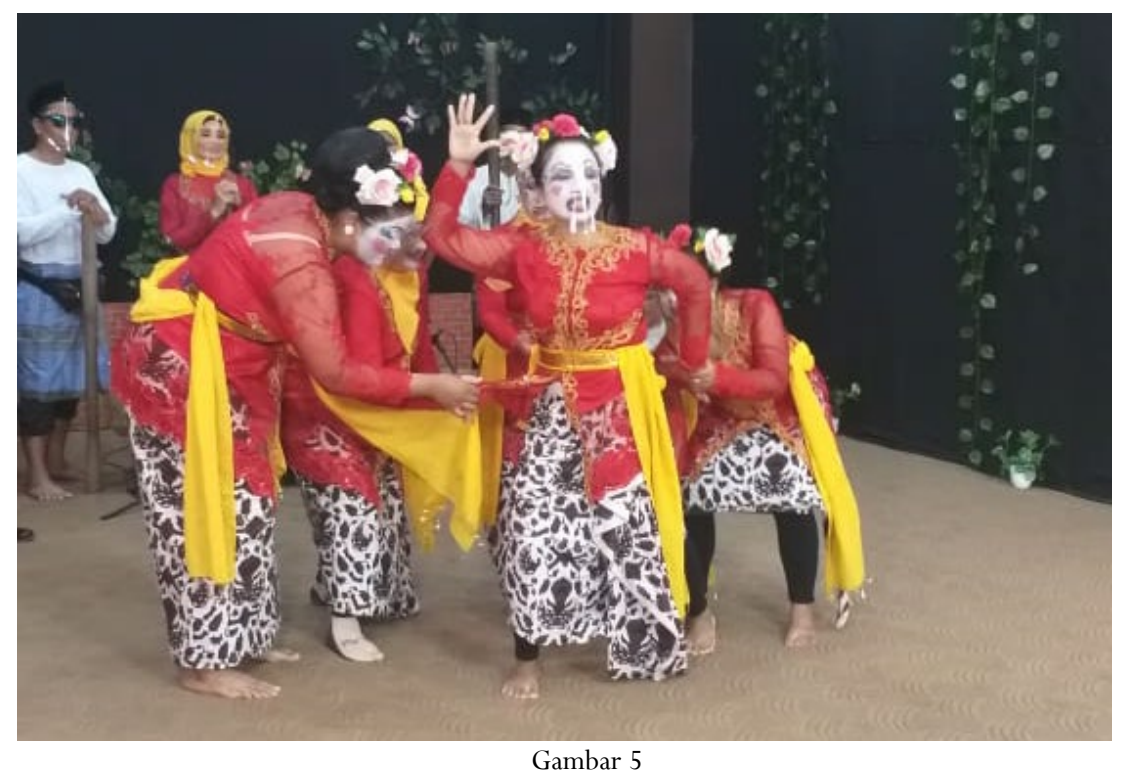

Pementasan Gojeg Lesung bersama Dinas Kesenian Kab. bantul

(Dokumentasi: Rano, 2021)

\section{UCAPAN TERIMA KASIH}

Ucapan terima kasih penyuluh sampaikan kepada Lembaga Pengabdian Masyarakat ISI Yogyakarta yang telah memberikan kesempatan untuk melaksanakan program penyuluhan seni ini. Sebagai rasa kagum, penyuluh menyampaikan ucapan terima kasih kepada segenap masyarakat Sabdodadi khususnya masyarakat sekitar Sanggar Kolingin yang dengan penuh keramahan menerima serta mengikuti rangkaian kegiatan penyuluhan seni ini dengan suasana kekeluargaan. Salam takjub juga kepada perangkat desa baik Ketua RT, Dukuh, dan Lurah yang dengan penuh perhatiannya mengikuti perkembangan proses penyuluhan ini dari awal hingga akhir.

\section{DAFTAR PUSTAKA}

Soedarsono. (1985). Gaya Hidup Masyarakat Jawa. Yogyakarta: Departemen Pendidikan dan Kebudayaan.

Sumarno, Rano. (2017). Metode Planting untuk Penyutradaraan Teater dalam Karya Cipta Seni Pertunjukan. Yogyakarta: Badan Penerbit ISI Yogyakarta.

Suratmin. (1991). Bentuk-Bentuk Peralatan Hiburan dan Kesenian Tradisional. Jakarta: Departemen Pendidikan dan Kebudayaan

Wicaksono F., dkk. (2020). Statistik Daerah Kabupaten Bantul. Yogyakarta: Badan Pusat Statistik Kabupaten Bantul. 
